\title{
Non-Traumatic Intracranial Hemorrhage in Adolescent
}

\section{Joana Vanessa Soares Silva ${ }^{1 *}$, Benedita Sousa Amaral Bianchi de Aguiar ${ }^{1}$, Eduardo Miguel Pereira da Costa ${ }^{1}$, António Adriano Gonçalves Vilarinho², Josué Augusto de Carvalho Pereira ${ }^{2}$ and Magalys Sotto Gómez Pereira ${ }^{1}$}

${ }^{1}$ Department of Pediatrics, Centro Hospitalar de Entre Douro e Vouga, Santa Maria da Feira, Portugal

${ }^{2}$ Pediatric Neurosurgery Unit, Department of Neurosurgery, Centro Hospitalar Universitário de São João, Porto, Portugal

*Corresponding author: Joana Vanessa Soares Silva, Department of Pediatrics, Centro Hospitalar de Entre Douro e Vouga, Santa Maria da Feira, Rua Dr. Cândido Pinho 5, 4520-211, Portugal, Tel: +351-913-177-892

\begin{abstract}
Background: Intracranial hemorrhage $(\mathrm{ICH})$ is a rare entity in pediatric age, that is responsible to high rates of morbidity and mortality. Vascular malformations, such as Arteriovenous malformation (AVM), are the main causes in this age group. Despite its congenital nature, AVM is less commonly discovered in children than in adults unless it complicates.

Case report: The authors present the clinical case of a 17-year-old boy, previously healthy, who suffered sudden focal neurologic deficits due to a hemorrhage located in the left frontal lobe. Radiological investigation revealed a left frontal AVM as the origin of $\mathrm{ICH}$. Preoperative functional Magnetic resonance imaging (MRI) revealed closeness of hemorrhage to the language and motor areas. In addition, the patient also presented as a complication a seizure. After surgical resection, he had a slight deterioration of his neurologic deficits.

Conclusion: AVMs are lesions rarely diagnosed in the pediatric population. Despite high survival rate observed, neurocognitive or functional impairments can have great impact on their autonomy and social functioning in the medium and long term.
\end{abstract}

\section{Keywords}

Adolescent, Intracranial hemorrhages, Arteriovenous malformations

\section{Introduction}

$\mathrm{ICH}$ is a rare condition diagnosed in pediatric age and leading to high rates of morbidity and mortality. The most common causes of nontraumatic $\mathrm{ICH}$ are vascular malformations such as AVM, aneurysms and cavernous angioma [1].

Brain AVM account for almost half of the cases of spontaneous ICH in children [2]. These vascular lesions could also present with seizures or headaches, being focal neurologic deficits quite unusual $[3,4]$.

Although its congenital origin, AVM is less common in children and usually it does not come to clinical attention unless it complicates [5].

The authors report a clinical case of an adolescent with sudden focal neurologic deficits due to an $\mathrm{ICH}$ in context of a ruptured brain AVM.

\section{Case Report}

The authors report a clinical case of a 17-year-old boy, previously healthy, who was admitted to the emergency department due to a sudden onset of right hemifacial paraesthesia, dysarthria and sialorrhea. No other symptoms, like dysphagia, headache, vomiting or fever, occurred. He had no history of major head trauma, seizures, spontaneous bruising or bleeding. On admission, his blood pressure was $116 / 58 \mathrm{mmHg}$, heart rate was 70/min, and he had a Glasgow coma scale score 15/15. His neurological examination was significant for a partial motor aphasia and a right- sided central facial nerve palsy.

Non-contrast brain Computed tomography (CT) revealed a $2.3 \times 1.5 \times 3.0 \mathrm{~cm}$ hematoma in the left frontal lobe with mild surrounding edema, but without mass

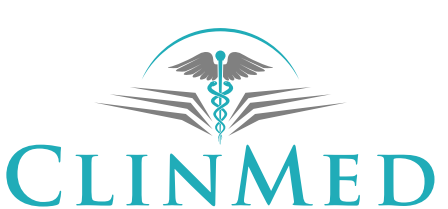

INTERNATIONAL LIBRARY
Citation: Silva JVS, Aguiar BSAB, Costa EMP, Vilarinho AAG, Pereira JAC, et al. (2021) Non-Traumatic Intracranial Hemorrhage in Adolescent. Neurosurg Cases Rev 4:057. doi.org/10.23937/26434474/1710057

Accepted: February 13, 2021; Published: February 15, 2021

Copyright: (c) 2021 Silva JVS, et al. This is an open-access article distributed under the terms of the Creative Commons Attribution License, which permits unrestricted use, distribution, and reproduction in any medium, provided the original author and source are credited. 


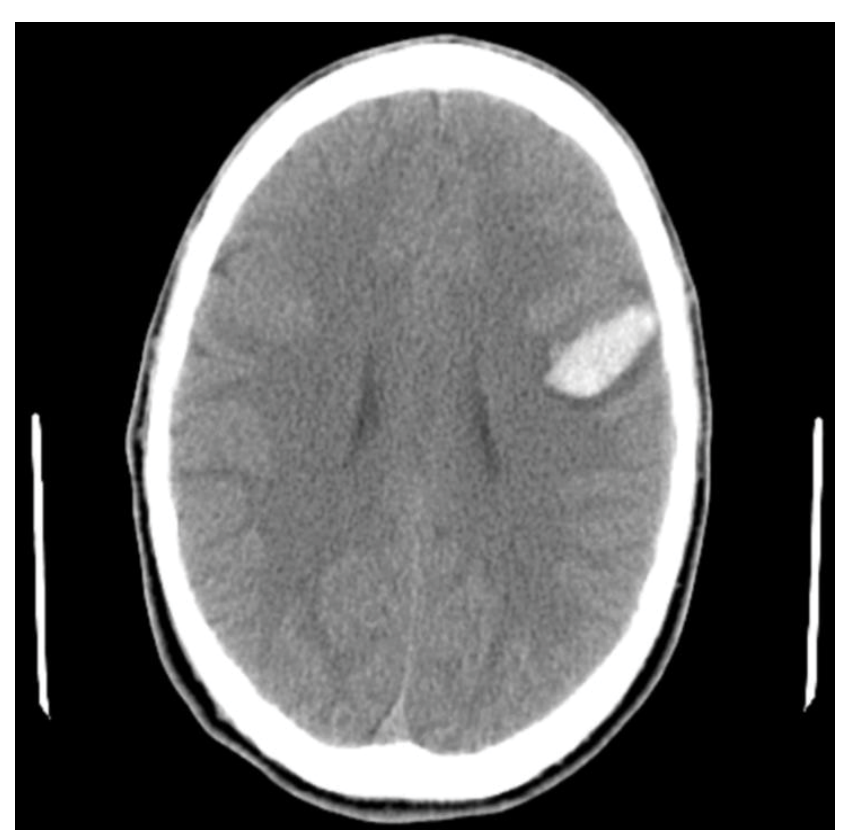

Figure 1: Preoperative computed tomography scan showed an intracranial hematoma in the left frontal lobe. effect on the ventricular system (Figure 1).

Considering the hypothesis of rupture of AVM, the patient was transferred to a tertiary hospital. While under clinical observation, he presented with a generalized tonic-clonic seizure and for which valproic acid was initiated.

Cerebral angiography (Figure 2) confirmed the existence of a left frontal AVM nidus $(2.1 \times 2.3 \mathrm{~cm})$ with predominant arterial supply from cortical branches of the middle left cerebral artery and superficial venous drainage to the left transverse sinus.

Functional MRI demonstrated activation of the cortex of the precentral gyrus, adjacent to the perilesional edema, to the right hand motor paradigm. The language paradigms demonstrated activation in the left frontal region (Broca area), adjacent to the hemorrhage.

Endovascular treatment was not considered due to vascular features of AVM with multiple arterial feeders, being cure less probable. Furthermore, the long latency
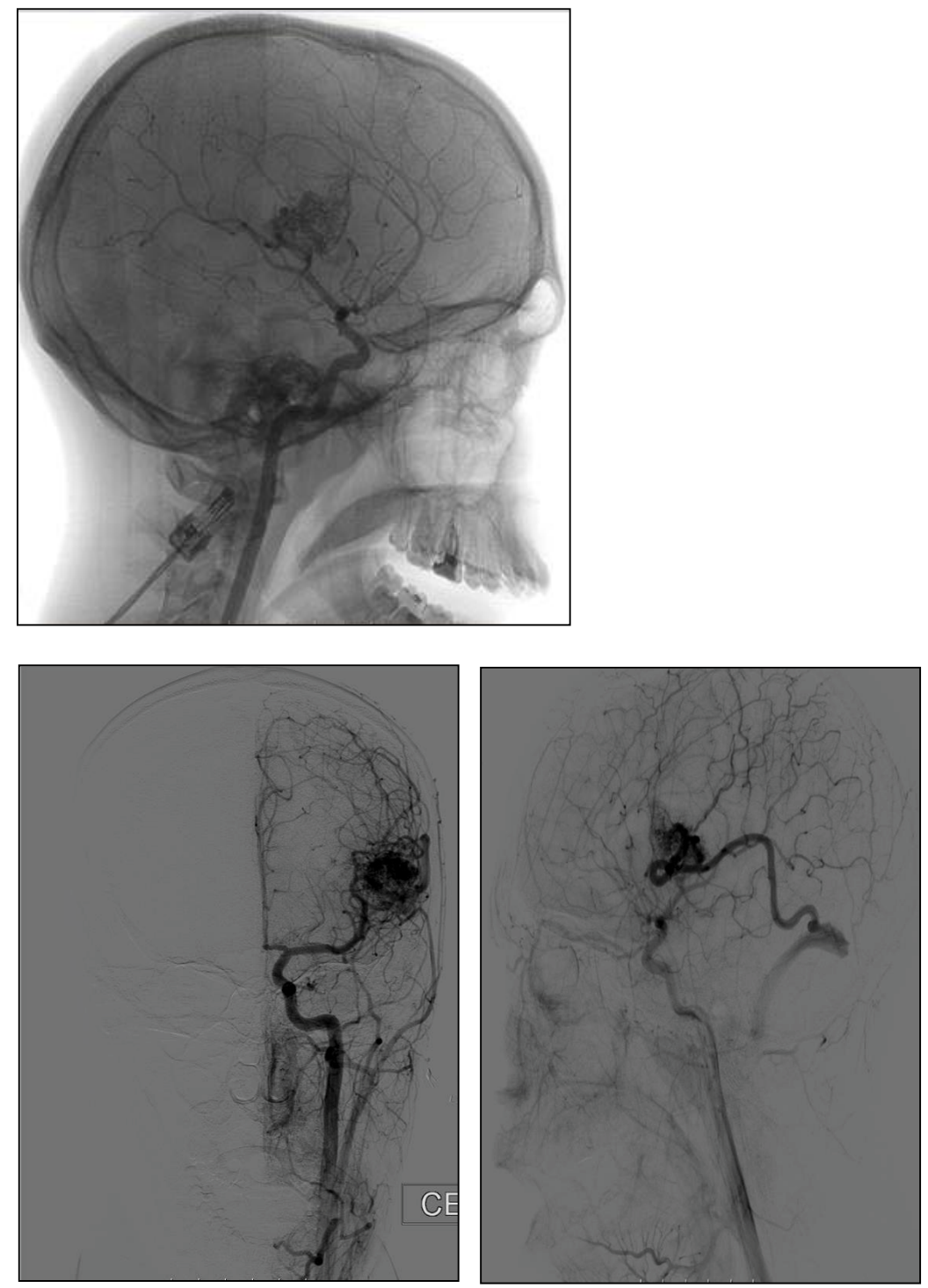

Figure 2: Cerebral angiography showing a left frontal AVM nidus with predominant arterial supply from cortical branches of the middle cerebral artery and superficial venous drainage to the left transverse sinus. 

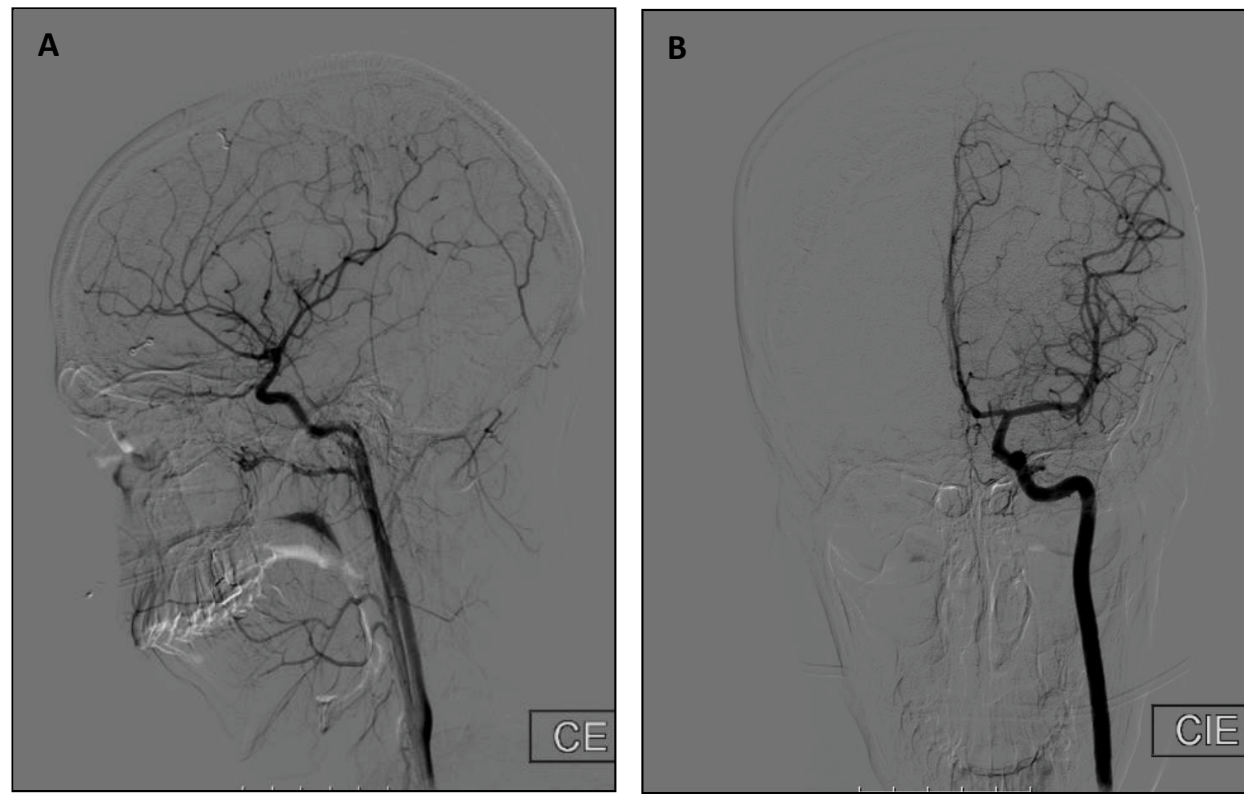

Figure 3: Postoperative. (A) Lateral; (B) Anteroposterior cerebral angiograms of the left internal carotid artery revealing no residual AVM.

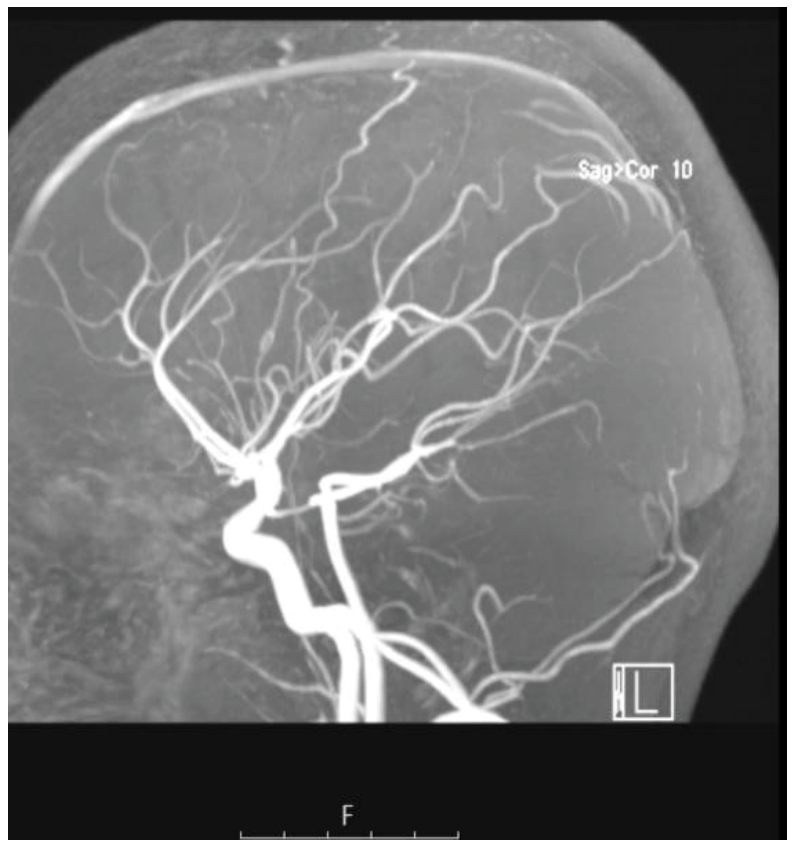

Figure 4: Control magnetic resonance angiography showed no arteriovenous malformations.

period of radiosurgery (2-4 years), in which hemorrhage risk remains, made it not a therapeutic option in this clinical case.

Surgical resection of the AVM (Spetzler-Martin grade II) was performed without major immediate complications but there was a slight deterioration of previous neurological deficits with right arm paresis. Postoperative cerebral angiography revealed no residual AVM (Figure 3). The rehabilitation program was maintained. He gradually recovered motor abilities and regained normal language function. The control magnetic resonance angiography showed no arteriovenous malformations (Figure 4). He remained clinically asymptomat- ic and without seizures, suspending valproate after 18 months.

\section{Discussion}

The distinction between traumatic and nontraumatic ICH sometimes may be challenging, with trauma being the most common cause in pediatric population. In nontraumatic cases, etiological causes differ from the adults, associating mainly to identifiable structural lesions like cerebral vascular lesions or neoplasms $[6,7]$. Among the main types of vascular malformations, brain AVM account for $40 \%$ to $90 \%$ of $\mathrm{ICH}$ in pediatric age $[6,8,9]$.

The pathogenesis of AVM is not completely understood, but a combination of genetic and environmental factors may play a role in its formation $[5,10]$.

Despite being rarely diagnosed in children, they carry a higher rate of rupture compared with adults [3]. Untreated AVM involves an annual risk of hemorrhage between $2-4 \%$ [3]. In our clinical case, there were no risk factors related to anatomic and vascular features that have impact in hemorrhage rates. It was a vascular malformation with a superficial venous drainage, a supratentorial location and without any associated aneurysms.

The presenting symptoms are influenced to anatomic and vascular features of the AVM, but also children's age $[4,11]$. Despite being the most frequently clinical manifestation in children, $\mathrm{ICH}$ is not the only clinical consequence, and many cases develop seizure, as in our patient. Some AVM characteristics observed, like frontal nidus location, middle cerebral artery feeders, superficial venous drainage, absence of associated aneurysms, and male gender and younger age, are linked to occurrence of seizures [12-14]. Focal neurologic deficits may 
be others findings, less common and usually related to mass effect or brain tissue damage due to hemorrhage. In some cases, neurological deficit can arise due to a vascular steal that causes hypoperfusion of areas not related to AVM [4].

Its diagnosis usually involves imaging techniques including $\mathrm{CT}, \mathrm{MRI}$ and angiography. $\mathrm{CT}$ has low sensitivity for detecting brain AVMs, but it is important in the face of suspicion of ruptured AVM to evaluate the hematoma. However, cerebral angiography remains to be the gold standard for the diagnosis of vascular malformations [3]. It is also important in posttreatment follow-up [11].

Treatment aims to obliterate or resect vascular lesion, preventing recurrence of hemorrhage and restoring neurologic function, in case of neurologic deficit due to mass effect or vascular steal. In face of brain tissue damage caused by hemorrhage, surgery does not aim at recovering from deficits, but at preventing subsequent hemorrhage [5].

Contrary to unruptured AVMs, the cases with prior history of AVM rupture are at higher risk of subsequent hemorrhage. The interventional treatment is indicated for most cases and occurs generally four to six weeks after the hemorrhage. Only cases with an increased risk of recurrent hemorrhage are treated acutely [15]. In addition, other complications may result from AVM resection like brain tissue damage. In order to prevent this, some preoperative neuroimaging tests can be performed as functional MRI and Diffusion tensor imaging (DTI), that is able to identify fiber tracts and eloquent areas in cortex $[3,16]$. After resection and despite having been performed this type of imaging technique, a slight and transient worsening of his neurological deficits happened.

Despite high survival rate observed in the pediatric population and complete resection of AVM, neurological, cognitive and adaptive behavior impairments can have great impact on their autonomy and social functioning in the medium and long term, especially in the case of persistent deficits after hemorrhage or treatment $[2,6]$.

\section{Funding}

There were no external funding sources for the realization of this paper.

\section{Conflicts of Interest}

There are no conflicts of interest to report.

\section{Authors' Contributions}

All authors had substantial contribution to the writing and editing of the manuscript, and also in its final approval.

\section{References}

1. Abbas Q, UI Ain Merchant Q, Nasir B, UI Haque A, Salam $B$, et al. (2016) Spectrum of intracerebral hemorrhage in children: A report from picu of a resource limited country. Crit Care Res Pract.

2. Ding D, Starke RM, Kano H, Mathieu D, Huang PP, et al. (2017) International multicenter cohort study of pediatric brain arteriovenous malformations. Part 1: Predictors of hemorrhagic presentation. J Neurosurg Pediatr 19: 127-135.

3. El-Ghanem M, Kass-Hout T, Kass-Hout O, Alderazi YJ, Amuluru K, et al. (2016) Arteriovenous malformations in the pediatric population: Review of the existing literature. Interv Neurol 5: 218-225.

4. Mohr JP, Kejda-Scharler J, Pile-Spellman J (2013) Diagnosis and treatment of arteriovenous malformations. Curr Neurol Neurosci Rep 13: 324.

5. Niazi TN, Klimo P, Anderson RCE, Raffel C (2010) Diagnosis and management of arteriovenous malformations in children. Neurosurg Clin N Am 21: 443-456.

6. Boulouis G, Blauwblomme T, Hak JF, Benichi S, Kirton A, et al. (2019) Nontraumatic pediatric intracerebral hemorrhage. Stroke 50: 3654-3661.

7. Sporns PB, Psychogios M-N, Fullerton HJ, Lee S, Naggara $O$, et al. (2020) Neuroimaging of pediatric intracerebral hemorrhage. J Clin Med.

8. Guedon A, Blauwblomme T, Boulouis G, Jousset C, Meyer $P$, et al. (2018) Predictors of outcome in patients with pediatric intracerebral hemorrhage: Development and validation of a modified score. Radiology 286: 651-658.

9. Beslow LA, Licht DJ, Smith SE, Storm PB, Heuer GG, et al. (2010) Predictors of outcome in childhood intracerebral hemorrhage: A prospective consecutive cohort study. Stroke 41: 313-318.

10. Santos R, Aguilar-Salinas P, Entwistle JJ, Aldana PR, Beier $A D$, et al. (2018) De novo arteriovenous malformation in a pediatric patient: Case report and review of the literature. World Neurosurg 111: 341-345.

11. Derdeyn CP, Zipfel GJ, Albuquerque FC, Cooke DL, Feldmann E, et al. (2017) Management of brain arteriovenous malformations: A scientific statement for healthcare professionals from the american heart association/american stroke association. Stroke.

12. Ding D, Starke RM, Quigg M, Yen C-P, Przybylowski CJ, et al. (2015) Cerebral arteriovenous malformations and epilepsy, Part 1: Predictors of seizure presentation. World Neurosurg 84: 645-652.

13. Josephson CB, Rosenow F, Al-Shahi Salman R (2015) Intracranial vascular malformations and epilepsy. Semin Neurol 35: 223-234.

14. Panagopoulos D, Markogiannakis G, Themistocleou M (2020) Ruptured arteriovenous malformation anterior to the brainstem to a child with subsequent spontaneous thrombosis: Case Report and Literature Review. Am J Case Rep.

15. Barr JC, Ogilvy CS (2012) Selection of treatment modalities or observation of arteriovenous malformations. Neurosurg Clin N Am 23: 63-75.

16. Zhao B, Cao Y, Zhao Y, Wu J, Wang S (2014) Functional MRI-guided microsurgery of intracranial arteriovenous malformations: Study protocol for a randomised controlled trial. BMJ Open.
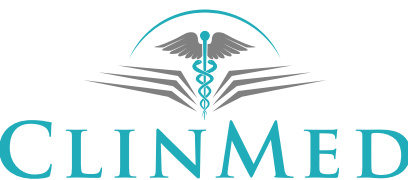

INTERNATIONAL LIBRARY 